\title{
Roteiro geológico e paleontológico nos municípios de Castro e Tibagi, Paraná - Brasil
}

\author{
Geological and Paleontological roadmap in Castro and Tibagi \\ municipalities, Paraná state, Brazil.
}

\section{Guía geológico y paleontológico en los municipios de Castro y Tibagi, estado de Paraná, Brasil}

\author{
William Mikio Kurita Matsumura \\ williammatsumura@gmail.com \\ Universidade Federal do Rio Grande do Sul \\ Elvio Pinto Bosetti \\ elvio.bosetti@pq.cnpq.br \\ Universidade Estadual de Ponta Grossa
}

Resumo: Opresente trabalho apresenta um roteiro geológico epaleontológico destinado a pesquisadores e professores de instituições de ensino superior. São descritos vinte afloramentos destacando-se seções-tipo, contatos geológicos, afloramentos clássicos e inéditos que apresentam peculiaridades relevantes, permitindo o acompanhamento de sucessões litológicas, estratigráficas, sedimentológicas e paleobiológicas entre o intervalo Ordoviciano Inferior a Carbonífero Superior, nos municípios de Castro e Tibagi, estado do Paraná, Brasil.

Palavras-chave: Roteiro geológico. Bacia de Castro e do Paraná. Castro. Tibagi. Intervalo Ordoviciano Inferior - Carbonífero Superior.

Abstract: This paper presents a geological and paleontological roadmap for university researchers and professors. Twenty outcrops are described with emphasis on typesections, geological contacts, classic outcrops and relevant peculiarities that allow one to recognize lithological, stratigraphic, sedimentological and paleobiological succession between the Lower Ordovician to Upper Carboniferous interval in the Castro and Tibagi municipalities, Paraná state, Brazil.

Keywords: Geological Route. Castro and Paraná basins. Castro. Tibagi. Interval Lower Ordovician - Upper Carboniferous. 
Resumen: En este trabajo se presenta un guía geológico y paleontológico para los investigadores y profesores de las instituciones de educación superior. Veinte afloramientos se describen destacando secciones-tipo, contactos geológicos, afloramientos clásicos y inéditos con particularidades pertinentes, permitiendo seguimiento de sucesiones litológicas, estratigráficas, sedimentológicas y paleobiológicas entre el intervalo Ordovícico Inferior a Carbonífero Superior en los municipios de Castro y Tibagi, estado de Paraná, Brasil.

Palabras claves: Guía geológico. Cuenca del Castro y Paraná. Castro. Tibagi. Intervalo Ordovícico Inferior - Carbonífero Superior.

\section{INTRODUÇÃO}

Na região dos Campos Gerais do Paraná, os trabalhos de campo coordenados pelo Grupo Palaios (UEPG/CNPq) nos últimos 20 anos têm contribuído no levantamento e na exploraçãocientífica deafloramentosfossilíferos. Essas pesquisas, além de promover oresgate do patrimônio paleontológico local, têm possibilitado o desenvolvimento de pesquisas na área da tafonomia (BOSETTI et al., 2009; 2011; 2012; HORODYSKI et al., 2012; ZABINI et al., 2010; 2012), paleontologia de invertebrados (ZABINI et al., 2007; COMNISKEY, 2011; GHILARDI et al., 2011; SCHEFFLER et al., 2011; MYSZYNSKI et al., 2012), paleoicnologia (BOSETTI et al., 2010; ZABINI \& BOSETTI, 2010), estratigrafia (GRAHN et al., 2010; 2011), paleobotânica (MATSUMURA et al., 2010; 2011; 2012; 2013), a formação de recursos humanos por intermédio de bolsas de iniciação científica e apoio técnico (ALMEIDA et al., 2009; PENTEADO et al., 2010; POSPIESZ \& BOSETTI, 2011; SEDORKO et al., 2011), mestrado (CRUZ, 2008; PEYERL, 2010; MATSUMURA, 2010; COMNISKEY, 2011; MYSZYNSKI, 2012) e doutorado (ZABINI, 2011), garantindo, assim, o avanço do conhecimento científico sobre a Paleontologia do Devoniano do estado do Paraná.

Essas pesquisas também proporcionaram estudos em colaboração com pesquisadores de diversas universidades brasileiras (UFRGS, USP, UNESP, UERJ, UFRJ, UNISINOS, dentre outras).

Ao longo desse período, foram levantados mais de 40 afloramentos rochosos distribuídos nos municípios de Ponta Grossa, Tibagi, Jaguariaíva, Arapoti, Palmeira e Ventania no estado do Paraná. Nos últimos anos, a pesquisa foi desenvolvida principalmente no município de Tibagi, onde se concentra a maioria dos afloramentos estudados. Cabe ressaltar que, além da pesquisa científica, trabalhos de campo objetivando o ensino para alunos do curso de graduação em Ciências Biológicas (Licenciatura e Bacharelado), Geografia (Licenciatura e Bacharelado), Licenciatura em Geografia (Ensino à Distância) e pós-graduação em Geografia (Mestrado em Gestão do Território) têm sido efetuados.

Sob essas perspectivas, o presente trabalho reúne os principais afloramentos geológicos e apresenta um roteiro geológico e paleontológico destinado a pesquisadores e professores de instituições de ensino superior. Os afloramentos estão localizados ao longo das margens das estradas e rodovias localizadas nos municípios de Castro e Tibagi, no estado 
do Paraná. Devido ao conteúdo fossilífero, um maior enfoque é dado ao período Devoniano.

São descritos para o roteiro vinte afloramentos que se iniciam nas rochas vulcânicas e vulcanoclásticas ordovicianas da Bacia de Castro. Em seguida e estratigraficamente acima, abrange as rochas glaciais Neoordovicianas da Formação lapó (Supersequência Rio Ivaí) e as rochas flúvio/costeiro e marinhas siluro-devonianas das formações Furnas, Ponta Grossa e São Domingos (Supersequência Paraná), encerrando com as rochas glaciogênicas Neocarboníferas do Grupo Itararé (Supersequência Gondwana I), pertencentes à Bacia do Paraná (Figura 1).

\section{CONTEXTO GEOLÓGICO BACIA DE CASTRO}

A Bacia de Castro é preenchida pelo Grupo Castro e consiste em um depósito vulcano-sedimentar cambro-ordoviciano aflorante na porção centro-leste do estado do Paraná. Abrange os municípios de Carambeí, Castro e Piraí do Sul e ocupa uma área total de 900 $\mathrm{km}^{2}$ (Figura 1). Moro et al., (1994) subdividiram o grupo em três associações litológicas, definidas a partir da base em: (i) Associação Tronco; (ii) Associação Piraí do Sul; e (iii) Associação Tirania.

\section{BACIA DO PARANÁ}

A Bacia do Paraná compreende uma vasta província sedimentar intracratônica ocorrente no centro-leste da América do Sul $\left(1.600 .000 \mathrm{~km}^{2}\right)$, ocupando parte da Argentina, Uruguai, Paraguai e sul do Brasil. Milani et al., (1998) subdividiram o registro estratigráfico da Bacia do Paraná em seis supersequências deposicionais de segunda ordem, distribuídas desde o Neo-ordoviciano até o Neo-cretáceo na forma de pacotes rochosos, materializando cada um deles intervalos temporais com algumas dezenas de milhões de anos de duração e separados por superfícies de discordância de caráter inter-regional. O presente roteiro contém afloramentos pertencentes às supersequências Rio Ivaí, Paraná e Gondwana I.

No estado do Paraná, a Formação Iapó (Supersequência Rio Ivaí) é a unidade mais antiga da bacia, sendo litologicamente representada por uma sucessão vertical de fácies muito pouco espessas (FARIA \& PEREIRA, 1994). Segundo Assine et al., (1996), trata-se de uma fina unidade de origem glacial Neo-ordoviciana, geralmente com espessura inferior a $20 \mathrm{~m}$, que apresenta fácies composta por diamictitos maciços de cores diversas, em matriz síltico-arenosa com seixos pingados, facetados e estriados.

A sucessão siluro-devoniana (Supersequência Paraná), aflorante na borda leste da bacia, é representada litoestratigraficamente pelo Grupo Campos Gerais (GRAHN, 1992; GAUGRIS \& GRAHN, 2006; GRAHN et al., 2011) e engloba as formações Furnas, Ponta Grossa e São Domingos (incluso Membro Tibagi). Litologicamente, é composta por folhelhos argilosos, silticos argilosos, siltitos e arenitos a arenitos conglomeráticos. 
O Grupo Itararé contém os registros sedimentares da glaciação gondwânica Neopaleozoica na Bacia do Paraná (MILANI et al., 2007). Na borda leste da bacia, esse grupo é subdividido litoestratigraficamente a partir da base pelas formações Campo do Tenente, Mafra e Rio do Sul (SCHNEIDER et al., 1974). Na região em estudo, o Grupo Itararé é representado pelo Arenito Barreiro, uma unidade informal que denomina os arenitos conglomeráticos que se sobrepõem, em discordância erosiva, aos folhelhos devonianos da Formação São Domingos.

Figura 1. Mapa geológico com a localização dos pontos de parada nos municípios de Castro e Tibagi - PR

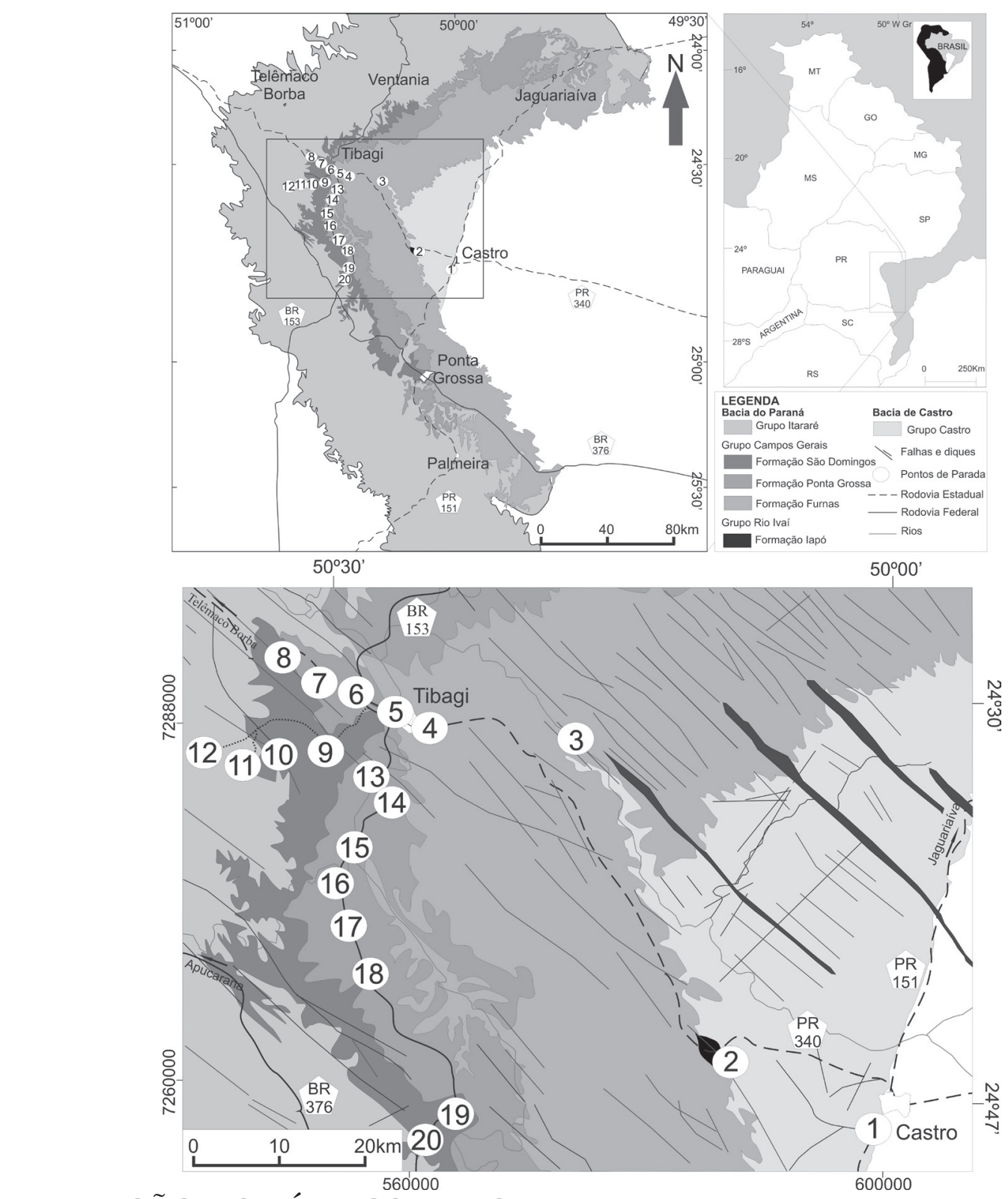

\section{DEFINIÇÃO DO PÚBLICO-ALVO}

De acordo com Carvalho; Da-Rosa (2008a; 2008b), os roteiros geológico-paleontológicos, além de fornecer o acesso e a localização dos sítios fossilíferos, podem também facilitar a depredação dos mesmos se não houver monitoramento adequado. Assim, o presente 
trabalho buscou definir um público-alvo para o roteiro proposto, em concordância com a atual legislação sobre os afloramentos fossilíferos brasileiros (BRASIL, 1988).

Esse roteiro é um instrumento de auxílio didático e apoio científico destinado ao público que objetiva desenvolver aulas práticas de campo e pesquisa científica na região. Essas atividades contribuem para a preservação dos afloramentos e proporcionam a geração de conhecimento científico. Com base nesses critérios, foram identificados quatro perfis de usuários potenciais do roteiro: (i) o Perfil I é representado por pesquisadores vinculados a instituições de ensino superior e pesquisa, que objetivam a realização de pesquisa científica na região; (ii) no Perfil II enquadram-se os professores de instituições de ensino superior, que buscam acesso aos afloramentos didáticos para desenvolver aulas práticas de campo, objetivando, principalmente, o ensino e a coleta de material geológico-paleontológico; (iii) o Perfil III abrange os professores das séries iniciais ( $1^{\mathrm{a}}$ a $4^{\mathrm{a}}$ séries) e do Ensino Básico de Ciências, Biologia e Geografia, que objetivam o ensino com ênfase em aulas práticas; (iv) o Perfil IV compreende os geoturistas, modalidade de turista que busca na geodiversidade um recurso turístico de lazer, recreação e conhecimento.

O roteiro aqui apresentado propôs a utilização do Patrimônio Fossilífero para o desenvolvimento de pesquisas e aulas práticas. Destina-se aos perfis que possuem conhecimento específico sobre a coleta e o processamento do material fóssil, auxiliando no desenvolvimento de suas atividades e evitando a perda das informações científicas dos depósitos fossilíferos, pois cada exemplar fóssil é único e insubstituível. Muitas informações (taxonômicas, tafonômicas, estratigráficas e paleoecológicas) podem ser extraídas a partir de uma coleta sistematizada e controlada. Inúmeras informações são perdidas apenas quando a procedência do fóssil é desconhecida. Assim, definiu-se que o público-alvo que o presente trabalho pretende atingir são os perfis I e II.

\section{CONSTRUÇÃO E ORGANIZAÇÃO DO ROTEIRO GEOLÓGICO E PALEONTO- LÓGICO}

Os afloramentos que compõem o roteiro foram selecionados utilizando-se dos seguintes critérios: (i) Seções-tipo e afloramentos clássicos de longa data conhecidos pela comunidade científica; (ii) Afloramentos inéditos; e (iii) Afloramentos com peculiaridades relevantes, como conteúdo paleontológico, contatos geológicos, eventos de crise biótica, dentre outros. Esses critérios auxiliaram na construção de um roteiro geológico e paleontológico que utiliza todo o conjunto de rochas ocorrentes na região, que, além de incluir afloramentos clássicos do Devoniano, também substitui e complementa afloramentos já degradados ou antropizados e de difícil acesso.

Para cada afloramento, foram construídas seções colunares apresentando os seguintes itens: 1) descrição litológica, 2) estruturas sedimentares e 3) conteúdo fossilífero ocorrente. Todas as colunas podem ser acessadas na íntegra em Matsumura (2010) disponível nos endereços (http://www.bicen-tede.uepg.br/tde_busca/arquivo.php?codArquivo=569; http://www.bicen-tede.uepg.br/tde_busca/arquivo.php?codArquivo=570; http:// www.bicen-tede.uepg.br/tde_busca/arquivo.php?codArquivo=571; http://www.bicen-tede.uepg.br/tde_busca/arquivo.php?codArquivo=572). 
O roteiro foi organizado em três formas de percursos (maior, intermediário e menor), delimitados a partir da disponibilidade dos usuários em dias de trabalho (Figura 2). $\mathrm{O}$ percurso menor fornece ao usuário 13 afloramentos que podem ser visitados em apenas um dia de trabalho, percorrendo $193 \mathrm{~km}$. O percurso intermediário abrange 16 afloramentos que podem ser visitados em dois dias de trabalho, percorrendo $203 \mathrm{~km}$. O percurso maior apresenta os 20 afloramentos que podem ser visitados em três dias de trabalho, totalizando uma trajetória de 215 km, conforme Tabela 1.

Figura 2. Mapa apresentando os três percursos diferentes de desenvolvimento do roteiro

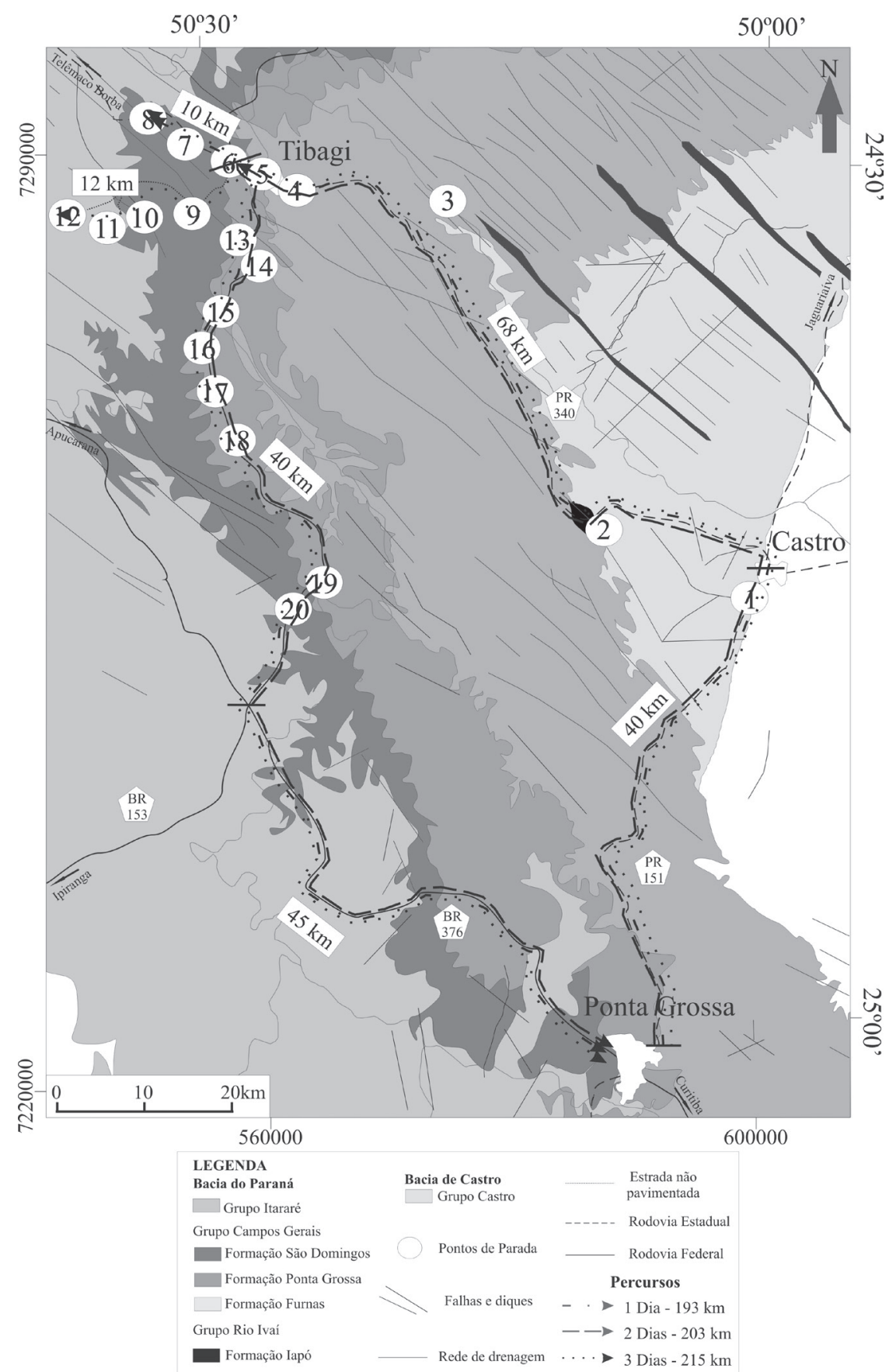


Tabela 1. Distribuição dos pontos de parada do roteiro nos diferentes percursos propostos

\begin{tabular}{|c|c|c|c|}
\hline 오 & $x$ & $x$ & $x$ \\
\hline$\stackrel{\oplus}{\Gamma}$ & $x$ & $x$ & $x$ \\
\hline$\stackrel{\infty}{\leftarrow}$ & $x$ & $x$ & $x$ \\
\hline$\stackrel{\sim}{\sim}$ & $x$ & $x$ & $x$ \\
\hline$\stackrel{\bullet}{\sim}$ & $x$ & $x$ & $x$ \\
\hline$\stackrel{2}{\sim}$ & $x$ & $x$ & $x$ \\
\hline$\underset{\nabla}{\Psi}$ & $x$ & $x$ & $x$ \\
\hline$\stackrel{m}{\sim}$ & $x$ & $x$ & $x$ \\
\hline$\stackrel{\sim}{\sim}$ & & & $x$ \\
\hline$\mp$ & & & $x$ \\
\hline 움 & & & $x$ \\
\hline 0 & & & $x$ \\
\hline$\infty$ & & $x$ & $x$ \\
\hline$\sim$ & & $x$ & $x$ \\
\hline 0 & $x$ & $x$ & $x$ \\
\hline م & $x$ & $x$ & $x$ \\
\hline$\nabla$ & $x$ & $x$ & $x$ \\
\hline$m$ & & $x$ & $x$ \\
\hline N & $x$ & $x$ & $x$ \\
\hline- & $x$ & $x$ & $x$ \\
\hline 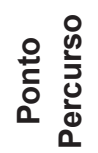 & 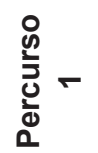 & 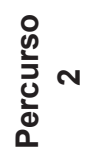 & 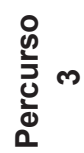 \\
\hline
\end{tabular}




\section{ROTEIRO GEOLÓGICO E PALEONTOLÓGICO PONTO DE PARADA 1}

O afloramento está localizado na PR-151, km 290, no município de Castro. Compreende uma seção de $7 \mathrm{~m}$ de espessura que representa uma fácies riolítica da Associação Tronco (Bacia de Castro - Ordoviciano inferior).

\section{PONTO DE PARADA 2}

O afloramento está localizado na PR-340, km 219, na Serra de São Joaquim, a oeste do município de Castro. A seção apresenta $19 \mathrm{~m}$ de espessura, onde, na base, é registrado 2 m de diamictitos cinza-azulados da Formação Iapó (Bacia do Paraná - Ordoviciano superior). Sobrepostos, em contato discordante, encontram-se $15 \mathrm{~m}$ de arenitos grossos com intercalações de níveis conglomeráticos pertencentes à Formação Furnas (Bacia do Paraná - Pridoliano/Lochkoviano). O conjunto é granodecrescente em direção ao topo, com redução progressiva dos termos conglomeráticos (cf. ASSINE, 1996).

\section{PONTO DE PARADA 3}

O afloramento localiza-se dentro do Parque Estadual do Guartelá (acesso pela PR340, a $42 \mathrm{~km}$ de Castro). O parque é uma Unidade de Conservação, portanto, a prospecção de material geológico é restrita apenas para pesquisa científica. É necessário o pagamento de taxa de entrada para visitação. A seção pode ser visualizada a partir do mirante do parque e possui espessura superior a $250 \mathrm{~m}$, apresentando na base as rochas vulcânicas do Grupo Castro, rochas glaciais da Formação Iapó e as três Unidades da Formação Furnas (cf. ASSINE, 1996).

\section{PONTO DE PARADA 4}

O afloramento está localizado no km 60 da PR-340, na entrada do município de Tibagi. A seção possui aproximadamente $16 \mathrm{~m}$ de espessura. A base é representada por arenitos médios a finos portadores de estratificação cruzada sigmoidal e planar, intercalados com camadas centimétricas de argilito a siltito médio, contendo fragmentos vegetais. No nível dos 10 m da seção, é evidenciado o contato entre formações Furnas e Ponta Grossa, e esse limite constitui uma superfície transgressiva de ravinamento gerada durante a transgressão Neo-praguiana/Eo-emsiana, com um hiato de aproximadamente $4 \mathrm{Ma}$ (GRAHN et al., 2010). Os pelitos da Formação Ponta Grossa são representados por camadas de siltito médio a fino cinza-médio, micáceo, fossilífero (típica fauna Malvinocáfrica), intercalados com lentes de arenito fino portadoras de estrutura micro-hummocky (HCS). 


\section{PONTOS DE PARADA 5, 6 E 7}

Os afloramentos localizam-se ao longo da rodovia PR-340, nos km 266, 270 e 271,5, respectivamente. Compreendem seções de até $20 \mathrm{~m}$ de espessura, representados por um conjunto de fácies sílticas e areníticas amareladas, muito fossilíferas, pertencentes às formações Ponta Grossa (os pontos 5 e 6, Eo-Emsiano) e São Domingos (Ponto 7, Neo-emsiano).

Figura 3. Vista geral dos Pontos de Parada. A - Ponto de Parada 1, PR-151, km 290; B - Ponto de Parada 2, PR-340, km 219, note o contato entre as formações Iapó e Furnas; C - Ponto de Parada 3, vista a partir do mirante do Parque Estadual do Guartelá, note a exposição das três unidades da Formação Furnas; D Ponto de Parada 4, PR-340, km 60, entrada da cidade de Tibagi, note o contato entre as formações Furnas e Ponta Grossa; E - Ponto de Parada 5, PR-340, km 266; F - Ponto de Parada 6, PR-340, km 270; G - Ponto de Parada 7, PR-340, km 271,5; H - Ponto de Parada 8, PR-340, km 280.
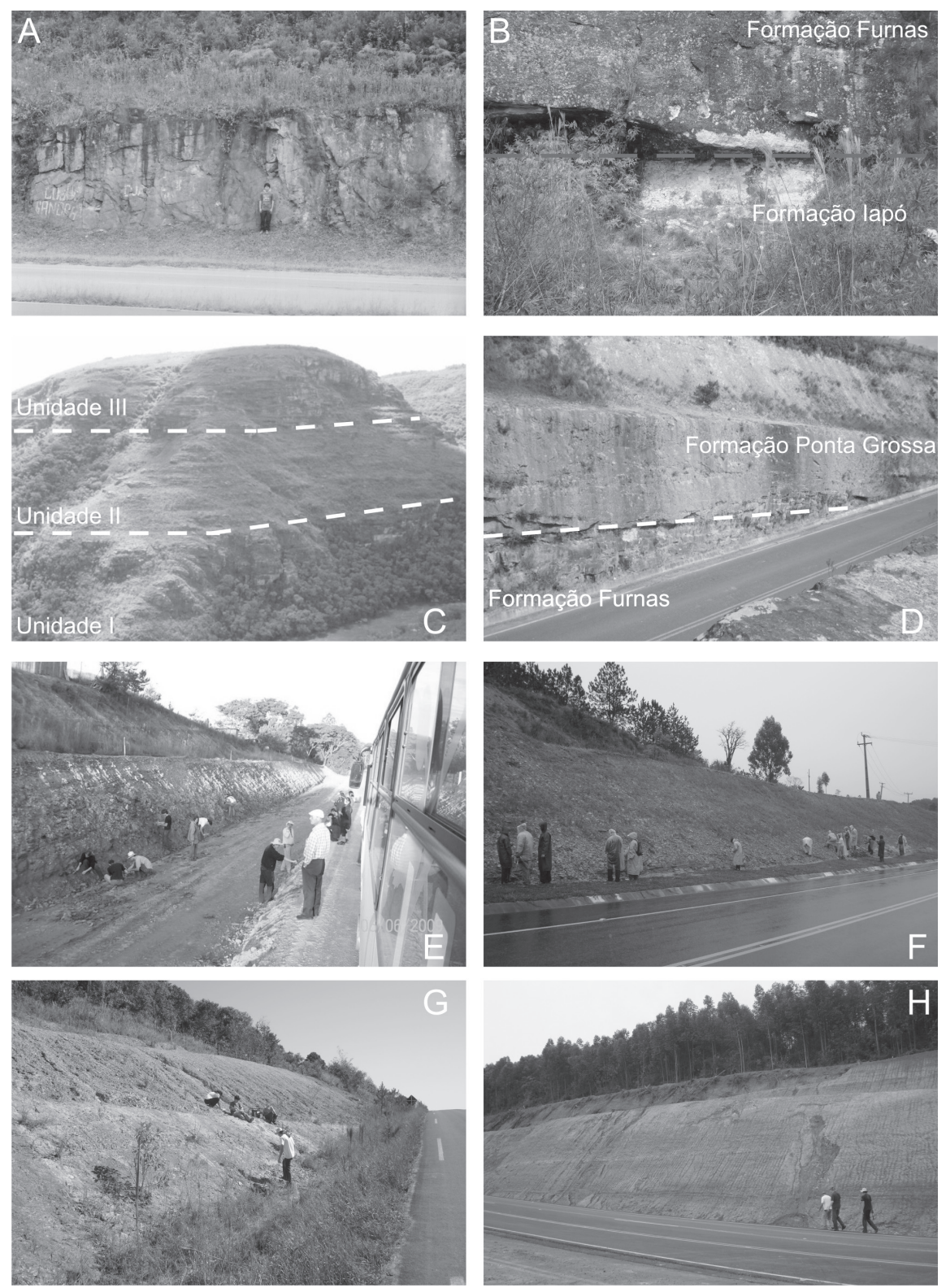


\section{PONTOS DE PARADA 8, 9 E 10}

O Ponto de Parada 8 encontra-se na rodovia PR-340, no km 280. Os Pontos de Parada 9 e 10 localizam-se no bairro São Domingos, no município de Tibagi. Todos os afloramentos compreendem um conjunto de fácies sílticas amareladas, intensamente fraturadas, pouco fossilíferas, pertencentes à Formação São Domingos (passagem Neoeifeliano-Givetiano). Esses pontos são de suma importância, pois registram um momento de extinção e crise biótica (Evento Kačák) da fauna Malvinocáfrica registrada pelos fenótipos subnormais de tamanho (Efeito Lilliput; $c f$. BOSETTI et al., 2011). O topo do Ponto de Parada 10 registra o contato discordante e erosivo entre a Formação São Domingos e o Arenito Barreiro (Grupo Itararé - Neocarbonífero).

\section{PONTOS DE PARADA 11 E 12}

Ambos os Pontos de Parada localizam-se dentro de áreas particulares, Pousada Puxa-Nervo e Pousada Salto Santa Rosa, respectivamente. A visitação é permitida mediante o pagamento de taxa de entrada e a prospecção de material geológico é proibida. Os afloramentos são pertencentes ao Arenito Barreiro (Grupo Itararé - Neocarbonífero) e possuem espessura superior a $25 \mathrm{~m}$. Litologicamente, são representados por arenitos finos a grossos, portadores de estratificação cruzada planar e sigmoidal, intercalados com níveis de arenitos conglomeráticos com seixos angulosos e estriados.

\section{PONTOS DE PARADA 13 E 14}

Localizam-se na rodovia BR-153, km 211 e km 211,5, respectivamente. Compreendem seções de até $30 \mathrm{~m}$ de espessura representados por um conjunto de fácies de siltito médio a grosso, micáceo, maciço, muito bioturbado, intercalado por folhelhos de coloração cinza escura. Sobrepostos, encontram-se um pacote de folhelho síltico, cinza escuro, com presença de braquiópodes linguliformes (Orbiculoidea baini e O. bodenbenderi) e rinconeliformes (Australocoela palmata, Australospirifer iheringi, Australostrophia e Schuchertella), moluscos bivalves (Edmondia sp.), gastrópodes e tentaculitídeos, além de trilobites calmoniídeos e icnofósseis diversos, pertencente à Formação São Domingos (Neo-emsiano). 
Figura 4. Vista geral dos Pontos de Parada. A - Ponto de Parada 9, estrada de acesso ao bairro São Domingos; B - Ponto de Parada 10, estrada de acesso ao bairro São Domingos, note o contato entre a Formação São Domingos e o Grupo Itararé; C - Ponto de Parada 11, Pousada Salto Puxa-Nervos; D Ponto de Parada 12, Pousada Salto Santa Rosa; E - Ponto de Parada 13, BR-153, km 211; F - Fóssil de Australospirifer iheringi do Ponto de Parada 13.
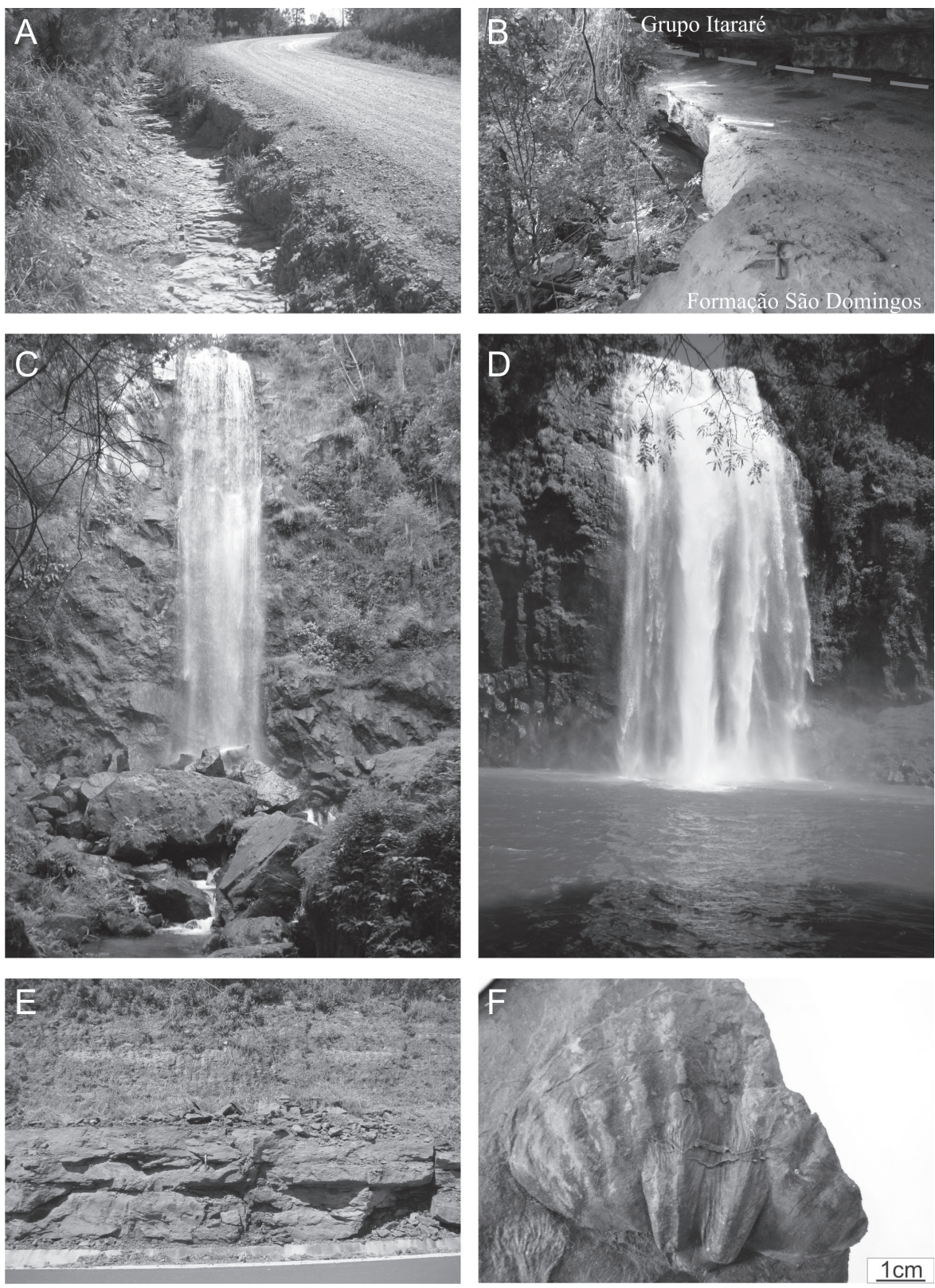

\section{PONTO DE PARADA 15}

Localiza-se na rodovia BR-153, $\mathrm{km}$ 214. O afloramento possui $28 \mathrm{~m}$ de espessura, em que a base da seção é representada por um pacote de siltito fino a médio, com presença de braquiópodes linguliformes (Orbiculoidea baini e Gigadiscina collis) e rinconeliformes (Australocoelia palmata, Schuchertella sp. e Australostrophia sp.), além de icnofósseis Zoophycos isp. Intercaladas, ocorrem camadas de arenitos finos a grossos portadores de 
estrutura HCS de pequeno e grande porte. Esse afloramento está inserido estratigraficamente na Formação São Domingos (Neo-emsiano).

\section{PONTO DE PARADA 16}

O afloramento encontra-se na BR-153, km 217. A seção apresenta 8 m de espessura, e a base inicia-se com um pacote de $2 \mathrm{~m}$ de folhelho síltico cinza-escuro, muito bioturbado, com a presença de braquiópodes lingulídeos preservados em concreções. Acima, ocorre uma camada de argilito esbranquiçado, folhelhoso, com a presença de braquiópodes rhynchonelliformes, moluscos bivalves e gastrópodes, além de trilobitas calmoniídeos. Esse ponto é pertencente à Formação São Domingos (Neo-emsiano).

\section{PONTO DE PARADA 17}

O afloramento está localizado na BR-153, km 220. A seção apresenta 10,5 m de espessura, e a base inicia-se com uma fácies de siltito fino, cinza-escuro, maciço, com presença de icnofósseis Zoophycos isp, e braquiópodes do gênero Australospirifer sp. Intercaladas ocorrem lentes de arenito fino com estrutura HCS. Acima desse nível, é registrada uma camada de folhelho síltico, amarelado, muito fossilífero, sendo comum a presença do braquiópode Orbiculoidea baini e moluscos bivalves. Esse afloramento está inserido estratigraficamente na Formação São Domingos (Neo-emsiano).

\section{PONTO DE PARADA 18}

O afloramento localiza-se na BR-153, km 223. A seção apresenta 44 m de espessura, e a base inicia-se com uma camada de arenito médio, amarelado, micáceo com estrutura HCS. Acima desse pacote, é registrada uma camada de arenito grosso, maciço, com abundância de braquiópodes rhynchonelliformes do gênero Australospirifer sp. Sobreposta, encontra-se uma camada de folhelho síltico. Níveis fossilíferos são observados no topo da seção, com predominância de braquiópodes linguliformes e peças mandibulares de escolecodontes.

\section{PONTOS DE PARADA 19}

Localiza-se na BR-153, km 236. O afloramento possui 5,5 m de espessura, e a seção inteira constitui uma camada de argilito, finamente laminado, de coloração cinza escuro, e icnofósseis atribuídos possivelmente a marcas de rolamento (Roll marks, BOSETTI et al., 2010) são encontrados na base do afloramento (Formação São Domingos - Eo-givetiano). 


\section{PONTOS DE PARADA 20}

Localiza-se na BR-153, $\mathrm{km} 238$. O afloramento possui aproximadamente $6 \mathrm{~m}$ de espessura e pertence à Formação São Domingos (Eo-givetiano). O afloramento é composto a partir da base por uma camada de siltito fino a médio, laminado e fraturado. Sobreposta ocorre uma camada de arenito grosso, maciço, conglomerático, com pequenos seixos. Acima desse pacote são registrados $0,5 \mathrm{~cm}$ de siltito grosso fraturado. Capeando toda a seção, os arenitos do Grupo Itararé encontram-se em contato discordante e erosivo.

Figura 5. Vista geral dos Pontos de Parada. A - Ponto de Parada 14, BR-153, km 211,5; B - Ponto de Parada 15, BR-153, km 214; C - Icnofósseis de Zoophycos isp. do Ponto de Parada 15; D - Ponto de Parada 16, BR-153, km 217; E - Ponto de Parada 17, BR-153, km 220; F - Ponto de Parada 18, BR-153, km 223; G Ponto de Parada 19, BR-153, km 236; H - Ponto de Parada 20, BR-153, km 238.
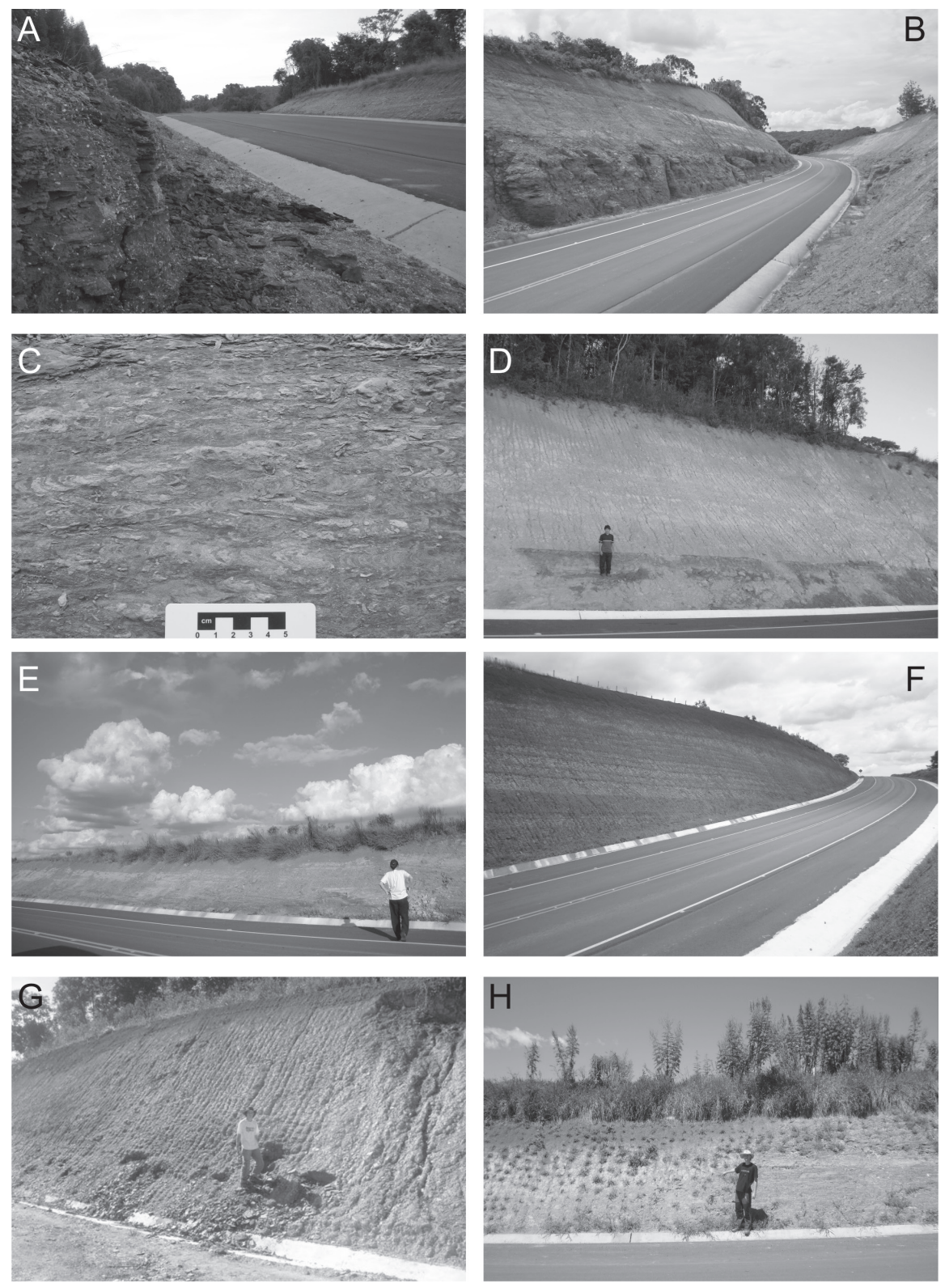


\section{CONSIDERAÇÕES FINAIS}

Os municípios de Castro e Tibagi (PR) apresentam substancial potencial geocientífico (geológico e paleontológico) para o desenvolvimento de roteiros de campo voltados à aulas práticas e/ou à pesquisa básica e aplicada. $\mathrm{O}$ roteiro aqui proposto permite $\mathrm{o}$ acompanhamento de sucessões litológicas, estratigráficas, sedimentológicas e paleobiológicas entre o lapso Ordoviciano Inferior - Carbonífero Superior na região dos Campos Gerais do Paraná. O roteiro comporta o desenvolvimento em três percursos alternativos, envolvendo um número variado de afloramentos a serem visitados. A definição do roteiro passando por pontos geocientíficos relevantes contribui para o conhecimento e a inerente preservação do patrimônio natural.

\section{AGRADECIMENTOS}

Os autores agradecem ao Conselho Nacional de Desenvolvimento Científico e Tecnológico (CNPq), pelo apoio através da concessão de bolsas (Processo 141979/2011-9) e auxílios (processos 401796/2010-8; 479474/2011-0), fundamentais para a realização deste trabalho.

\section{REFERÊNCIAS}

ALMEIDA, Alisson Wachtel; MATSUMURA, Willian Mikio Kurita; ZABINI, Carolina; BOSETTI, Elvio Pinto. Caracterização paleontológica do afloramento Sutil da Formação Ponta Grossa (Devoniano), na região sul do município de Ponta Grossa-PR. XVIII Encontro Anual de Iniciação Científica, 2009, Londrina, Anais de resumo. UEL, CD.

ASSINE, Mário Luiz. Aspectos da estratigrafia das sequências pré-carboníferas da Bacia do Paraná no Brasil. São Paulo, 1996. Tese (Doutorado em Geociências) Instituto de Geociências, Programa de PósGraduação em Geologia Sedimentar, USP.

ASSINE, Mário Luiz; PERINOTTO, José Alexandre de Jesus; ALVARENGA, Carlos José Souza de. A Formação Iapó: Registro Glacial no Limite Ordoviciano/Siluriano, Bacia do Paraná, Sul do Brasil. SIMPÓSIO SUL-AMERICANO DO SILURO DEVONIANO - PALEONTOLOGIA E ESTRATIGRAFIA. Ponta Grossa, Anais de resumo, Ponta Grossa: Gráfica Planeta, 1996, p. 289-298.

BOSETTI, Elvio Pinto; GODOY, Luiz Carlos; MYSZYNSKI, Lucinei José; HORODYSKI, Rodrigo Scalise; ZABINI, Carolina. Interpretação paleoambiental na sequência basal da Formação Ponta Grossa (Devoniano) do município de Ponta Grossa, Paraná, Brasil. Terr@Plural, Ponta Grossa, v. 3, n. 1, jan./jul. 2009, p. 137156,

BOSETTI, Elvio Pinto; ZABINI, Carolina; HORODYSKI, Rodrigo Scalise. Cephalopoda 'roll marks' in the Paraná Basin? I LATIN AMERICAN SYMPOSIUM ON ICHNOLOGY, São Leopoldo, Anais de resumo, UNISINOS, v. 1, 2010, p. 25-25.

BOSETTI, Elvio Pinto; GRAHN, Yngve; HORODYSKI, Rodrigo Scalise; MENDLOWICZ MAULLER, Paula; BREUER, Pierre; ZABINI, Carolina. An earliest Givetian "Lilliput Effect" in the Paraná Basin, and the collapse of the Malvinokaffric shelly fauna. Paläontologische Zeitschrift, v. 85, n. 1, mar. 2011, p. 49-65.

BOSETTI, Elvio Pinto; GRAHN, Yngve; HORODYSKI, Rodrigo Scalise; MENDLOWICZ MAULLER, Paula. The first recorded decline of the Malvinokaffric Devonian fauna in the Paraná Basin (southern Brazil) and its cause; taphonomic and fossil evidences. Journal of South American Earth Sciences, n. 37, ago. 2012, p. 228-241. 
BRASIL. Constituição de 1988. Constituição da República Federativa do Brasil: promulgada em 5 de outubro de 1988. São Paulo: Saraiva, 1988, p. 168 (Série Legislação Brasileira).

CARVALHO, Ismar Souza de; DA-ROSA, Átila Augusto Stock. Paleontological Tourism in Brazil: Examples and Discussion. Arquivos do Museu Nacional. Rio de Janeiro, v. 66, n. 1, jan./mar.2008a, p. 271-283.

CARVALHO, Ismar Souza de; DA-ROSA, Átila Augusto Stock. Patrimônio paleontológico no Brasil: relevância para o desenvolvimento socioeconômico. Memórias e Notícias, Nova Série, Coimbra, v. 3, 2008b, p. 15-28.

COMNISKEY, Jeanninny Carla. Paleontologia dos Discinidae (Brachiopoda: Linguliformea) da sucessão devoniana da Bacia do Paraná, Estado do Paraná, Brasil: Revisão sistemática, distribuição geográfica e estratigráfica. Ponta Grossa, 2011. Dissertação (Mestrado em Gestão do Território) Programa de PósGraduação em Geografia, UEPG.

CRUZ, Suzana de Fátima Camargo da. Paleontologia e Geografia: uma abordagem teórico-metodológica a partir dos sítios paleontológicos existentes na área urbana de Ponta Grossa, Paraná, Brasil. Ponta Grossa, 2008. Dissertação (Mestrado em Gestão do Território) Programa de Pós-Graduação em Geografia, UEPG.

FARIA, Márcia de Melo; PEREIRA, Egberto. Análise faciológica preliminar da Formação Iapó - Bacia do Paraná. CONGRESSO BRASILEIRO DE GEOLOGIA. 38, 1994. Balneário de Camboriú - SC. Anais de resumos, SBG. v. 1, p. 84-85.

GAUGRIS, Kariny de Amorim; GRAHN, Yngve. New chitinozoan species from the Devonian of the Paraná Basin, south Brazil, and their biostratigraphic significance. Ameghiniana, v. 43, n. 2, 2006, p. 293-310.

GHILARDI, Renato Pirani; SCHEFFLER, Sandro Marcelo; HORODYSKI, Rodrigo Scalise; BOSSETI, Elvio Pinto. Ocorrência de macroinvertebrados pós eventoKAČÁK: considerações prévias sobre paleobiogeografia do Eogivetiano da Bacia do Paraná. XII PALEO PR/SC 2011, Mafra/SC. Anais de resumos, v. 1, p. 20-20.

GRAHN, Yngve. Revision of Silurian and Devonian Strata of Brazil. Palynology, Dallas, n. 16, 1992, p. $35-$ 61.

GRAHN, Yngve; MENDLOWICZ MAULLER, Paula; BREUER, Pierre; BOSETTI, Elvio Pinto; BERGAMASCHI, Sérgio; PEREIRA, Egberto. The Furnas/Ponta Grossa contact and the age of the lowermost Ponta Grossa Formation in the Apucarana Sub-basin (Paraná Basin, Brazil): integrated palynological age determination. Revista Brasileira de Paleontologia, v. 13, n. 2, 2010, p. 89-102.

GRAHN, Yngve; MENDLOWICZ MAULLER, Paula; BERGAMASCHI, Sérgio; BOSETTI, Elvio Pinto. Palynology and sequence stratigraphy of three Devonian rock units in the Apucarana Sub-basin (Paraná Basin, south Brazil): Additional data and correlation. Review of Paleobotany and Palynology. Vol. 198, 2013, p. 27-44.

HORODYSKI, Rodrigo Scalise; BOSETTI, Elvio Pinto; GHILARDI, Renato Pirani; SCHEFFLER, Sandro Marcelo; MATSUMURA, Willian Mikio Kurita; IANUZZI, Roberto; SEDORKO, Daniel. Tafonomia e paleoambientes da Seção Colunar Tibagi-Ventania, Tibagi-PR, Brasil (Formações Ponta Grossa e São Domingos). I SIMPÓSIO BRASILEIRO DE PALEOINVERTEBRADOS, Bauru. Boletim Paleontologia em Destaque (Rio de Janeiro), 2012, v. 1, p. 47-47.

MATSUMURA, Willian Mikio Kurita. Roteiro geológico nos municípios de Castro e Tibagi, PR - BRASIL. 2010. Dissertação (Mestrado em Gestão do Território) Programa de Pós-Graduação em Geografia, UEPG.

MATSUMURA, Willian Mikio Kurita; IANNUZZI, Roberto; BOSETTI, Elvio Pinto. Registro Paleobotânico do Devoniano do Paraná: Aplicações bioestratigráficas e implicações paleofitogeográficas. XIII REUNIÃO ANUAL DA SOCIEDADE BRASILEIRA DE PALEONTOLOGIA (PALEO PR/SC), 2011, Mafra. Anais de resumo, UNC, p. 19.

MATSUMURA, Willian Mikio Kurita; PINHEIRO, Esther Regina S.; IANNUZZI, Roberto; BOSETTI, Elvio Pinto. Registro de Interações Planta-Arthropoda no Devoniano Médio da Bacia do Paraná. I SIMPÓSIO BRASILEIRO DE PALEOINVERTEBRADOS, 2012, Bauru. Boletim Informativo da Sociedade Brasileira de Paleontologia - Edição Especial. UNESP - BAURU, p. 52. 
MATSUMURA, Willian Mikio Kurita; BOSETTI, Elvio Pinto; IANNUZZI, Roberto. Estudo tafonômico das plantas fósseis do Devoniano Médio do estado do Paraná, Brasil. XIV SIMPÓSIO BRASILEIRO De PALEOBOTÂNICA E PALINOLOGIA, Rio de Janeiro. Anais do Museu Nacional - UFRJ, 2013. p. 109.

MILANI, Edison José; FACCINI, Ubiratan Ferrucio; SCHERER, Claiton Marlon dos Santos; ARAUJO, Laury Medeiros de; CUPERTINO, José Antonio. Sequences and stratigraphic hierarchy of the Paraná Basin (Ordovician to Cretaceous), Southern Brazil. Boletim IG/USP, série científica v. 29, 1998, p. 125-173.

MILANI, Edison José; FRANÇA, Almério Barros; MEDEIROS, Rodi Ávila. Rochas geradoras e rochasreservatório da Bacia do Paraná, faixa oriental de afloramentos, Estado do Paraná. Boletim de Geociências da Petrobrás, Rio de Janeiro, n. 15, 2007, p. 135-162.

MORO, Renata de Paula Xavier; BONACIM, Elaine; SOARES, Paulo César. A Bacia de Castro. Boletim Paranaense de Geociências, n. 42, p. 43-58. 1994.

MYSZYNSKI, Lucinei José. Inserção do afloramento Curva II no contexto tafonômico e estratigráfico da Sequência Neopraguiana-Eoemsiana: interpretação paleoambiental do setor nordeste do sítio urbano de Ponta Grossa, Paraná, Brasil. 2012. Dissertação (Mestrado em Gestão do Território) Programa de PósGraduação em Geografia, UEPG.

MYSZYNSKI, Lucinei José; BOSETTI, Elvio Pinto ; MATSUMURA, Willian Mikio Kurita; HORODYSKI, Rodrigo Scalise; SEDORKO, Daniel. Interpretação Paleoambiental da Seção Neopraguiana/Eoemsiana (Formação Ponta Grossa), Município de Ponta Grossa, Paraná. XIV REUNIÃO ANUAL DA SOCIEDADE BRASILEIRA DE PALEONTOLOGIA (PALEO PR/SC), Ponta Grossa. Anais de resumo, UEPG, 2012. p. 13.

PENTEADO, Andressa Carla; HORODYSKI, Rodrigo Scalise; MATSUMURA, Willian Mikio Kurita; BOSETTI, Elvio Pinto Interpretação paleoambiental do afloramento Tibagi 3, Formação Ponta Grossa, Bacia do Paraná, Município de Tibagi-PR, Brasil. XIX ENCONTRO ANUAL DE INICIAÇÃO CIENTÍFICA, Guarapuava. Anais de resumo, v. 1. 2010.

PEYERL, Drielli. A trajetória do paleontólogo Frederico Waldemar Lange (1911-1988) e a História das Geociências. 2010. Dissertação (Mestrado em Gestão do Território) Programa de Pós-Graduação em Geografia, UEPG.

POSPIESZ, Bruna de Ávila; BOSETTI, Elvio Pinto. Estudo taxonômico dos braquiópodes do afloramento Curva II, Bacia do Paraná, Ponta Grossa, PR, Brasil. XX ENCONTRO ANUAL DE INICIAÇÃO CIENTÍFICA, Ponta Grossa. Anais de resumo, Ponta Grossa: UEPG, v. 1, p. 1-4. 2011.

SCHEFFLER, Sandro Marcelo; GHILARDI, Renato Pirani; HORODYSKI, Rodrigo Scalise; BOSETTI, Elvio Pinto. Os únicos equinodermas do Devoniano médio (Eogivetiano) da sub-bacia de Apucarana, estado do Paraná (Bacia do Paraná). XIII PALEO 2011 PR/SC, Mafra. Anais de resumos. Mafra: UNCv. 1, 2011, p. 8.

SCHNEIDER, Rubem, L.; MUHLMANN, Hilton; TOMMASI, E.; MEDEIROS, Rodi Ávila; DAEMON, Roberto Ferreira; NOGUEIRA, A. A. Revisão estratigráfica da Bacia do Paraná. CONGRESSO BRASILEIRO DE GEOLOGIA, 28, Porto Alegre, Anais de resumos. Sociedade Brasileira de Geologia, 1974, p. 41-65.

SEDORKO, Daniel; BOSETTI, Elvio Pinto; HORODYSKI, Rodrigo Scalise; MATSUMURA, Willian Mikio Kurita. Tafofácies de macroinvertebrados marinhos como ferramenta auxiliar para correlações estratigráficas de superfície: um exemplo do Neoemsiano da Bacia do Paraná. XII Reunião Regional da Sociedade Brasileira de Paleontologia (PR/SC), 2011, Cascavel. Anais de resumo, 2010, v. 1, p. 3.

ZABINI, Carolina. Integração da tafonomia e estratigrafia de sequências no estudo dos lingulídeos da sucessão devoniana da Bacia do Paraná. 2011. Tese (Doutorado em Geociências) - Instituto de Geociências, Programa de Pós-Graduação em Geociências, UFRGS.

ZABINI, Carolina; BOSETTI, Elvio Pinto. Devonian Lingulichnus in the Paraná Basin. I LATIN AMERICAN SYMPOSIUM ON ICHNOLOGY, São Leopoldo. Anais de resumos, 2010. v. 1, p. 68-68.

ZABINI, Carolina; BOSETTI, Elvio Pinto; MATSUMURA, Willian Mikio Kurita; HORODYSKI, Rodrigo Scalise. Lingulídeos: revisão dos conceitos morfo-anatômicos, fisiológicos, reprodutivos, paleoecológicos e a importância do grupo no Devoniano da região dos Campos Gerais do Paraná, Brasil. Revista Terr@ Plural, Ponta Grossa, 1, 1, jan.-jul., 2007, p. 123-141. 
ZABINI, Carolina; BOSETTI, Elvio Pinto; HOLZ, Michael. Taphonomy and taphofacies analysis of lingulid brachiopods from Devonian sequences of the Paraná Basin, Brazil. Palaeogeography, Palaeoclimatology, Palaeoecology, v. 292, 2010, p. 44-56.

ZABINI, Carolina; HOLZ, Michael; BOSETTI, Elvio Pinto; MATSUMURA, Willian Mikio Kurita; HORODYSKI, Rodrigo Scalise. Sequence Stratigraphy and Taphonomic Signatures of Marine Invertebrates: A Devonian (Pragian/Eifelian) Example of The Paraná Basin, Brazil. Journal of South American Earth Sciences, v. 33, 2012, p. 8-20.

Recebido em 22/07/2013

Aceito para publicação em 30/10/2013 